\title{
Percalços da Educação Infantil como direito da criança: análise da história e da legislação das décadas de 1980 e 1990
}

\section{Challenges of Early Childhood education as a children's right: analysis of the history and legislation of the 1980's and 1990's}

\author{
Maria Angélica Olivo Francisco Lucas* \\ Maria Cristina Gomes Machado**
}

\begin{abstract}
Resumo: Nesse artigo, discutimos a respeito da função da educação infantil entre o fim da ditadura militar até a aprovação da atual Lei de Diretrizes e Bases (LDB). Esse período se constitui em etapa importante para a história desse nível de ensino devido à produção de documentos fundamentais que reconhecem os direitos da criança, tais como a Constituição Federal (1988), o Estatuto da Criança e do Adolescente - ECA (1990) e a Política Nacional de Educação Infantil - PNEI (1994) - fontes deste estudo. O texto constitucional reconheceu-as como cidadãs, o ECA reforçou esse compromisso do Estado e a PNEI definiu condições adequadas para o desenvolvimento das crianças. Contudo, o atendimento com qualidade a toda a demanda caminha em passos lentos, ignorando o reconhecimento da especificidade dessa modalidade de ensino.

Palavras-chave: Educação. História das Políticas Educacionais. Educação Infantil.
\end{abstract}

\begin{abstract}
This article seeks to analyze the role of Early Childhood education in the period between the end of the Brazilian military dictatorship until the enactment of the current Lei de Diretrizes e Bases da Educação Nacional (National Educational Bases and Guidelines Law - LDB). This period represents a major step in the history of Early Childhood Education due to the development of documents that were essential to the acknowledgment of children's rights, such as the Constituição Federal (Federal Constitution - 1988), the Estatuto da Criança e do Adolescente (Child and Adolescent Statute - ECA) (1990) and the Política Nacional de Educação Infantil (National Policy for Early Childhood Education - PNEI) (1994). All of these documents were used as basis for this study. The constitutional text recognized children as citizens, while the ECA has strengthened this commitment from the part of the State. Similarly, the PNEI has defined the suitable conditions for children's overall development. However, the universal implementation of a quality service progresses slowly, since the specificity of this educational modality is yet to be fully recognized.
\end{abstract}

Keywords: Education. History of education policies. Early Childhood education.

* Professora da Universidade Estadual de Maringá - UEM. E-mail: <mangelicaofl@ibest.com.br>

** Professora da Universidade Estadual de Maringá - UEM/CNPq. E-mail: <mcgm.uem@gmail.com> 


\section{Introdução}

As últimas três décadas da história da educação brasileira constituem-se em uma etapa importantíssima para a história de educação infantil. O período coincide com as lutas para democratização da escola pública, no Brasil, em suas diversas modalidades: a Educação Infantil, o Ensino Fundamental e o Ensino Médio. O acesso e a permanência foram ampliados, bem como a educação passou a ser tratada como um direito. Contudo, sua universalização foi acompanhada pela ampliação dos problemas que revelam um quadro caótico marcado pela baixa qualidade de ensino. Observa-se que a busca pela qualidade do ensino tem sido a tônica das políticas educacionais direcionadas para o Ensino Fundamental e Médio, em que se constata o comprometimento de distintas instâncias governamentais. Entretanto, no caso específico da Educação Infantil, presenciam-se passos mais lentos no atendimento a toda a demanda, embora no âmbito legislativo tenhamos conquistado o reconhecimento da necessidade e especificidade dessa modalidade de ensino.

Como ocorreu esse processo? Quais foram os documentos oficiais que permitiram reconhecer o direito da criança de zero a seis anos à educação? Essas são as principais indagações que nortearam a elaboração deste texto. É importante atentarmos para o processo histórico que favoreceu a consolidação desse direito, destacando as dificuldades de sua garantia.

Com base no reconhecimento de que as instituições e garantias legais são produzidas por uma dada sociedade, consideramos importante compreender as condições materiais que levaram ao tratamento da Educação Infantil como um direito, ou seja, concebendo-a dialeticamente como provento e vantagem para a sociedade como um todo - em especial para as crianças pequenas -, bem como um "incômodo" para o Estado em suas diferentes esferas.

Rosemberg (2003) dividiu o espaço de tempo do movimento que tornou a Educação Infantil um direito em três grandes períodos ${ }^{1}$. O primeiro inicia-se no final dos anos 1970 e finda nos últimos anos da década de 1980. A abertura política após a ditadura militar delimita o início do segundo período, marcado pelas ações desenvolvidas por movimentos sociais que se mobilizaram em prol

\footnotetext{
${ }^{1}$ Existem outras e mais abrangentes periodizações para a história da educação infantil brasileira. Kramer (1987), por exemplo, a partir da periodização realizada por Moncorvo Filho (1926), dividiu a história da proteção à infância no Brasil em três períodos: no primeiro, que durou até o ano de 1874, destacam-se as casas dos expostos ou rodas que recebiam crianças pequenas, funcionavam com parcos recursos e em situações precárias de higiene, apresentando altas taxas de mortalidade; o segundo momento compreende o período entre 1874 e 1899, quando médicos, higienistas e industriais se preocuparam com os elevados índices de mortalidade infantil; o terceiro momento, de 1899 a 1930, é marcado pela criação do Instituto de Proteção à Infância, com o objetivo de construir creches e jardins de infância, despertando esferas do governo para os problemas infantis. Kramer (1987), com base no histórico organizado por Moncorvo Filho, estabelece um quarto período na história da educação infantil brasileira, que vai de 1930 a 1980 .
} 
da educação das crianças pequenas durante a Constituinte. O terceiro período começa em 1996 com a aprovação e implantação da atual Lei de Diretrizes e Bases da Educação Nacional (LDB).

Neste artigo, objetivamos discutir a respeito da função conferida à educação das crianças pequenas no decorrer do segundo momento da periodização, conforme explicitado anteriormente, marcado pelo fim da Ditadura Militar até a aprovação da LDB. Para alcançar tal objetivo faz-se necessário o cruzamento da história da educação infantil brasileira e das políticas públicas que tratam desse nível de escolaridade.

Compartilhamos com Oliveira (2002) da necessidade de adotarmos dois princípios apontados nos estudos dos campos anteriormente referenciados, visto que, primeiramente, devemos estar atentos às mudanças de concepções, crenças e valores que não acontecem em um passe de mágica. Isto implica considerar que as concepções de infância, de desenvolvimento, de educação, do papel do Estado e da sociedade para com a educação das crianças pequenas contribuíram para as propostas de políticas públicas e a elaboração de legislação educacional que materializaram essas mudanças. Dessa premissa, decorre a segunda proposição, pois as definições de políticas públicas educacionais expressam um contexto mais amplo que envolve a sociedade civil e os organismos governamentais, de modo a ser possível afirmar a correlação intrínseca entre a função conferida à educação das crianças de 0 a 6 anos com as mudanças políticas e econômicas da sociedade.

Para tanto, o presente artigo está organizado em quatro partes. Na primeira parte caracterizamos o período da história da educação infantil brasileira em análise, seguindo a periodização feita por Rosemberg (2003), cujo início é marcado pelo processo de abertura política após a ditadura militar, e é marcado, sobretudo, por ações desenvolvidas pelos movimentos sociais que se mobilizaram em prol da Constituinte. Trata-se de um período de intensa mobilização política, rico em discussões e propostas que envolviam a busca de uma função pedagógica ${ }^{2}$ para a educação das crianças pequenas, a ponto de influenciar não apenas a redação do texto constitucional, mas de outros documentos legais, especialmente os elaborados no início da década de 1990. A partir dessa caracterização, apresentamos as principais conquistas para a educação das crianças pequenas oriundas do texto da Constituição Federal (1988), do Estatuto da Criança e do Adolescente - ECA (1990) e da Política Nacional de Educação Infantil - PNEI (1994).

\footnotetext{
${ }^{2}$ Utilizamos esta expressão pautando-nos na formulada por Kramer (1987) e Abramovay e Kramer (1984) para definir a finalidade deste nível de ensino como aquela que toma a realidade e os conhecimentos das crianças como ponto de partida, ampliando-os por meio de atividades que tenham significado para elas e que promovam seu desenvolvimento.
} 


\section{Educação infantil como direito da criança e dever do Estado}

A forma de se conceber o papel do Estado no referido período, salienta Rosemberg (2002a), interferiu diretamente nos rumos da educação brasileira de uma forma geral, bem como na educação infantil. Até a década de 1980, aproximadamente, os serviços sociais em nosso país, entre eles a educação, foram organizados com base em dois critérios: ênfase em objetivos sociais com equidade, solidariedade e integração social; o papel central do Estado na organização, no financiamento e na provisão desses objetivos por meio de recursos públicos. Em consonância com essa concepção de Estado, a gestão governamental foi organizada de acordo com as políticas sociais, ou seja, dividida em setores: saúde, trabalho, previdência social, moradia e educação (VILLALOBOS, $2000^{3}$ apud ROSEMBERG, 2002a).

Essa concepção de política social orientou a inclusão da educação infantil no âmbito dos direitos educacionais e trabalhistas na atual Constituição, afirma Rosemberg (2002b), pois não apenas norteou o texto desta lei, como, para muitos dos profissionais e pesquisadores envolvidos com a área, também se configurou em modelo ideal de política para a educação infantil. Nesse momento, organizações multilaterais, como a Organização das Nações Unidas pela Educação, Ciência e Cultura (UNESCO) e o Fundo das Nações Unidas para a Infância (UNICEF) pouco atuaram na área da educação infantil brasileira: "A UNESCO orientava sua ação mais para a África; o UNICEF dava visibilidade a novos temas, como "meninos de rua" e prostituição infanto-juvenil e, no campo de educação infantil latino-americana, sua atenção voltou-se para Cuba" (ROSEMBERG, 2002b, p.12).

Como destacamos, o início das reformas no nosso sistema educacional foi dado pelo processo de elaboração da atual Constituição Federal. Conjuntamente, outros fatores - a vitória da oposição nas eleições nos principais estados, em 1982; a população em geral, em multidões, lotando as ruas e praças, reivindicando eleições diretas para presidente da República (movimento Diretas Já), em 1984; a eleição indireta do presidente Tancredo Neves, em 1985; e a convocação da Assembleia Nacional Constituinte - contribuíram para impulsionar reformas pela via da legislação no nosso sistema educacional. Vejamos como Munerato (2001, p. 30) sintetiza os anos 1980, enfatizando os movimentos sociais e a participação popular na elaboração da nova carta constitucional:

[...] a década de 80 constitui-se no momento em que a sociedade civil articulase em resistência ao governo militar que, enquanto poder, não atendia às necessidades da sociedade como um todo, por estar voltado para a política dos

${ }^{3}$ VILLALOBOS, Verônica Silva. O estado do bem-estar social na América Latina: necessidade de redefinição. Cadernos Adenauer, n. 1, p. 49-70, 2000. 
desmandos, corrupções, aproveitamentos próprios, distribuindo favores, num processo de opressão domesticadora da sociedade, tornando o assistencialismo uma prática incontrolável. Os movimentos gerais da sociedade articulamse e unem-se, em função da bandeira da participação popular, e passam a desempenhar um papel decisivo na elaboração de emendas populares e no consequente movimento de sensibilização popular para a conquista de sua adesão a essas propostas e sua subscrição.

No início dos trabalhos da Assembleia Nacional Constituinte, a participação popular foi reconhecida e incluída no regimento interno. Várias associações que já estavam organizadas mobilizaram-se para levar suas bandeiras às ruas, provocando muitos debates que envolviam, mormente, as políticas sociais para habitação, saúde, previdência social e educação (MUNERATO, 2001). Tratava-se de uma forma de despertar a população e, concomitantemente, sensibilizar os legisladores para essas questões, entre elas, a educação da criança pequena.

Campos (1986) aborda detalhadamente as dificuldades de incluir a educação da criança de 0 a 6 anos nos preceitos constitucionais. Por vivenciar esse momento, a autora deixa transparecer um relativo desânimo em relação à Assembleia Nacional Constituinte, instalada em 10 de fevereiro de 1987, devido, primeiramente, ao fato de ela ser composta por parlamentares eleitos na mesma ocasião em que foram escolhidos os governadores de cada estado, ou seja, em 1986, o que obscureceu o significado especial dessa eleição e minimizou a importância da elaboração de um novo texto constitucional para o país. Em segundo lugar, revela que antes e durante o processo de redação desse documento as forças mais conservadoras do país estavam unidas e recebendo apoio de esferas com grandes interesses econômicos, enquanto as forças mais progressistas e populares estavam, de forma geral, divididas ou desmobilizadas.

Apesar disso, Barreto (1995) caracteriza o final da década de 1980 como um momento de grande participação da sociedade civil e de organismos governamentais na discussão e afirmação dos direitos da criança, entre eles, o direito à educação. O movimento das mulheres, ao qual já nos referimos anteriormente, o Fórum de Defesa da Criança e do Adolescente e o movimento Criança e Constituinte foram responsáveis pela afirmação desses direitos.

Esses movimentos defendiam uma política integrada de educação da criança de 0 a 6 anos, opondo-se à concepção puramente assistencialista, pautada em programas não-formais, adotada até então pelos órgãos oficiais. Reivindicava-se que creches e pré-escolas fossem incluídas no novo texto constitucional não apenas como uma resposta ao direito da mulher à igualdade na sociedade, mas como um direito da criança à educação. Por isso, suas reivindicações eram aglutinadas em duas comissões: a do Conselho Nacional dos Direitos da Mulher 
(CNDM), vinculado ao Ministério da Justiça, e a da Comissão Nacional Criança e Constituinte ${ }^{4}$, sob responsabilidade do Ministério da Educação (MEC). Esta última, segundo Didonet (1992, p. 26),

[...] promoveu uma ampla campanha de conscientização sobre as questões da criança na sociedade brasileira, debates com os constituintes, sessões de estudo sobre a criança, produção e distribuição de textos para reflexão, estudo e debate nas escolas, nas instituições governamentais, nas organizações não governamentais (associações, clubes de serviço, igrejas, movimentos, etc.).

Comissões estaduais foram criadas em cada unidade da federação, e em vários municípios organizaram-se comissões semelhantes. As propostas encaminhadas foram analisadas e sintetizadas por delegados dessas comissões em dois encontros nacionais, resultando em um documento final, contendo várias propostas, que foi entregue aos membros da Assembleia Nacional Constituinte, sob a forma de emenda popular, acompanhada de 1.300.000 assinaturas. O Fórum da Defesa da Criança e do Adolescente enviou aos constituintes uma emenda popular com 85.000 assinaturas.

Com o envolvimento da sociedade civil organizada, pretendia-se que a educação infantil fosse concebida como um direito da criança e não apenas como um direito da mulher. Pautada em uma comunicação feita por Fúlvia Rosemberg em seminário promovido pelo Conselho Estadual da Condição Feminina de São Paulo, Campos (1986, p. 59) relaciona três razões para isso:

Primeiro, quando a vinculação existe somente em função do direito da mulher, a creche sofre as flutuações que a sociedade impõe ao trabalho da mulher. Segundo, incluindo-se a creche no item relativo à educação, está se rompendo, pelo menos ao nível do texto, com tudo aquilo que caracterizou a proposta de creche neste país como uma instituição assistencialista. Terceiro, entendendose a creche como uma instituição que deve ser oferecida à população como uma alternativa e não como uma substituta da família, resguarda-se, de um lado, o direito da mulher e da família optarem ou não por ela, porém, ao mesmo tempo, reforça-se a concepção de que a responsabilidade pela educação da criança pequena não é só da família, mas também da sociedade. (CAMPOS, 1986, p. 59).

No entanto, não havia à época unanimidade em relação a esta posição até mesmo entre educadores. Muitos argumentavam contrariamente, baseando-se no fato de o Brasil, naquela época, não ter universalizado o então $1^{\circ}$ grau, apesar

\footnotetext{
${ }^{4}$ Participaram dessa comissão: Ministério da Educação, da Saúde, do Trabalho, da Previdência e Assistência Social, da Justiça, da Cultura, Secretaria de Planejamento da Presidência da República, UNICEF, Organização Mundial para a Educação Pré-Escolar (OMEP), Ordem dos Advogados do Brasil (OAB), Federação Nacional de Jornalistas (FENAJ), Sociedade Brasileira de Pediatria (SBP), Conselho Nacional dos Direitos da Mulher (CNDM), Frente Nacional dos Direitos da Criança (FNDdC), Movimento Nacional de Meninos e Meninas de Rua (MNMMR). (DIDONET, 1992, p. 26).
} 
de este nível de escolaridade já constar como obrigatório na Constituição de 1967. Temia-se que a inclusão no novo texto constitucional do direito a outros níveis de escolaridade diminuísse a ênfase dada ao $1^{\circ}$ grau e repartisse os recursos disponíveis para a escola básica. Além disso, muitos educadores interpretaram de forma equivocada essas reivindicações, confundindo o direito à educação para as crianças de 0 a 6 anos, oferecida de forma gratuita pelo Estado, com a obrigatoriedade de frequência a creches e pré-escolas. Defendia-se naquela época, segundo Campos (1986, p. 61), a ideia de "[...] incluir a creche entre os demais serviços educacionais, ao lado da pré-escola, e ambas virem mencionadas na parte do texto constitucional dedicado à educação". Foi o que ocorreu, como a seguir veremos, detalhadamente.

\section{Os direitos da criança cidadã na atual Constituição Federal}

A Constituição Federal de 1988 representa um marco histórico na redefinição dos direitos de cidadania, tanto do ponto de vista dos direitos políticos, como dos direitos sociais. É dela que decorreram as leis que forneceram as diretrizes para as políticas de cada área social. Promoveu uma nova visão de seguridade social, segundo a qual todos os cidadãos têm o direito de serem assistidos pelo Estado em suas necessidades básicas, independentemente de serem contribuintes da previdência social, ou seja, estabelece-se o caráter universal das políticas básicas, a cujo acesso gratuito todos têm direito, como, por exemplo, a educação. (CRAIDY, 2002).

A atual carta magna é a mais extensa de todas as outras constituições brasileiras em matéria de educação, sendo detalhada em dez artigos específicos (Arts. 205 a 214) e figurando em quatro outros dispositivos (Arts. 22, XXIV; 23, V; 30, VI e Arts. 60 e 61 do Ato das Disposições Constitucionais Transitórias - ADCT). Trata da educação, ampliando seus direitos significativamente a diferentes níveis e modalidades. Assim, inclui, pela primeira vez, o direito da criança pequena ao atendimento em creches e pré-escolas, estendido a toda faixa etária de 0 a 6 anos, o que é considerado um marco na história da educação infantil brasileira. Pela primeira vez na história desse nível de escolaridade, a criança pequena foi considerada um cidadão de direitos. Nesta condição, tem, entre outros, o direito de ser atendida em creches e pré-escolas, e o Estado tem o dever de garantir esse atendimento com a qualidade e em quantidade suficiente para que a educação possa verdadeiramente ser adjetivada como democrática.

Vejamos o que afirma, entusiasticamente, o então deputado Ubiratan Diniz de Aguiar (1994, p. 58) a respeito do texto constitucional: 
Inquestionavelmente, a Constituição de 1988 é um documento exemplar no que concerne à garantia dos direitos fundamentais da pessoa humana e ao exercício da cidadania, tendo representado um avanço considerável no reconhecimento dos direitos da criança, em especial o seu direito à educação desde o nascimento. Nossa Carta Magna estabelece um patamar para a criança jamais alcançado na sociedade brasileira. Seus direitos são erigidos como prioridade absoluta. Em nenhuma outra parte, para nenhum outro assunto, a Constituição fala em prioridade, muito menos em absoluta... Realmente, na área dos direitos da infância, nossa Constituição atual é, sem dúvida, um marco fundamental.

O reconhecimento, no texto constitucional, da educação de 0 a 6 anos como um direito da criança e não apenas da mãe como trabalhadora foi resultado dos movimentos reivindicatórios e dos intensos debates que mobilizaram a sociedade civil em tomo da questão, anteriormente expostos. Em relação a essa questão, Oliveira (2002, p. 37) advoga:

Não são mais os pais, apenas, que têm direito a uma instituição de educação infantil para seus filhos, gerando um atendimento com vistas a substituí-los enquanto estão trabalhando. A criança passa a ter direito a uma educação que vá “além" da educação recebida na família e na comunidade, tanto no que diz respeito a profundidade de conteúdos, quanto na sua abrangência.

Autores como Campos, Rosemberg e Ferreira (2001), Oliveira (2002), Corrêa (2002) e Vieira (2007) ressaltam o caráter inaugural desta lei: é pela primeira vez que uma constituição brasileira reconhece, como direito da criança pequena, o acesso à educação em creches e pré-escolas; é pela primeira vez que nossa lei maior faz referência aos direitos específicos das crianças pequenas, fora do âmbito do Direito da Família. Isso significou, pelo menos no nível do texto constitucional, um grande passo em direção à superação do caráter assistencialista predominante nos programas voltados para essa clientela, conferindo caráter educacional às creches e pré-escolas.

O direito da criança pequena ao acesso à educação está incluído nos Arts. 205 e 208 da seção Da Educação. No primeiro, o direito à educação foi estendido às crianças com idade entre 0 e 6 anos por inclusão, uma vez que afirma ser a educação direito de todos (MUNERATO, 2001; AGUIAR, 1994). O segundo reafirma o dever do Estado para com a educação dessas crianças e considera creches e pré-escolas instituições equivalentes: "O dever do Estado com a educação será efetivado mediante a garantia de [...] atendimento em creche e pré-escola às crianças de zero a seis anos de idade” (BRASIL, 1988).

No entanto, é o Art. 227 do capítulo Da Família, Da Criança, Do adolescente e do Idoso que define, de forma mais abrangente, os direitos da infância brasileira: 
É dever da família, da sociedade e do Estado, assegurar à criança e ao adolescente, com absoluta prioridade, o direito à vida, à saúde, à alimentação, à educação, ao lazer, à profissionalização, à cultura, à dignidade, ao respeito, à liberdade e à convivência familiar e comunitária, além de colocá-los a salvo de toda forma de negligência, discriminação, exploração, violência, crueldade e opressão. (BRASIL, 1995, p. 102).

Essa concepção de criança como sujeito pleno de direitos é confirmada, de forma direta ou indireta, em outras partes da Constituição:

- o Art. $7^{\circ}$, incisos XVIII, XIX e XXV, do capítulo Dos Direitos Sociais reconhece como direitos do trabalhador a licença-gestação de 120 dias, a licença paternidade e a assistência gratuita aos filhos e dependentes desde o nascimento até seis anos de idade em creches e pré-escolas;

- o Art. 203 da seção Da Assistência Social define, entre os objetivos da assistência social, nos incisos I e II, a proteção à família, à maternidade, à infância, à adolescência e à velhice, bem como o amparo às crianças e aos adolescentes carentes, independentemente de contribuição à seguridade social;

- o parágrafo $4^{\circ}$ do Art. 212 da seção Da Educação define que os programas assistenciais inseridos no sistema educacional, programas suplementares de alimentação e assistência à saúde, por exemplo, podem ser estendidos a creches e pré-escolas.

A Constituição Federal (1988) recupera o caráter federativo da República brasileira, muito comprometido no regime autoritário, devido às medidas concentradoras de recursos e poder adotadas pelo governo central. Segundo Barretto (2000, p. 29),

Pela nova Carta Constitucional os municípios deixam de ser considerados apenas unidades administrativas, passando a entes federativos, aos quais são atribuídos recursos e autonomia em proporções maiores do que em todas as constituições anteriores. Além de competência própria para e1aborarem as leis referentes aos interesses locais, eles adquirem competências compartilhadas com as demais instâncias, que passam a cobrir um vasto espectro de assuntos, entre os quais a organização de seus respectivos sistemas de ensino.

De acordo com o Parágrafo $2^{\circ}$ do Art. 211 do texto constitucional, passam a ser de responsabilidade dos municípios, com o apoio dos Estados e da União, a oferta e a manutenção de programas de educação pré-escolar e de ensino fundamental. Quanto ao ensino fundamental, devido à história da sua expansão e à ambiguidade da Lei, a responsabilidade pode ser dos estados e dos municípios. Estas duas instâncias de poder são corresponsáveis pelo ensino fundamental. Quanto à educação infantil, a Lei não deixa margem à dúvida: é o município o seu responsável e provedor, apesar de ela apregoar a existência de um regime de colaboração entre as diferentes instâncias. (BARRET'TO, 2000). 
"A nova Constituição consagra, no plano da lei, o que os movimentos sociais já vinham reivindicando em várias partes do país". (CAMPOS; ROSEMBERG; FERREIRA, 2001, p. 16). Todavia, entre o idealizado no texto legal e a realidade educacional brasileira, em especial a destinada às crianças pequenas, havia uma grande distância.

Essa distância entre o plano real e o legal foi verificado pela Equipe de Pesquisa sobre Creches da Fundação Carlos Chagas, entre 1983 e 1989, ao estudar e diagnosticar a situação da educação das crianças de 0 a 6 anos em creches e pré-escolas. O primeiro estudo, realizado em 1983, intitulado Subsídios para elaboração de um programa nacional de atendimento à criança (POPPOVIC et al., $1983^{5}$ apud CAMPOS; ROSEMBERG; FERREIRA, 2001), apresenta, em seu início, um diagnóstico dos problemas e das tendências da educação infantil brasileira, cuja síntese será reproduzida a seguir. No estudo realizado dois anos após, intitulado 'Creches e pré-escolas no Brasil', Campos, Rosemberg e Ferreira (2001), analisando o atendimento à criança de 0 a 6 anos, no Brasil, durante a Década da Mulher (1975-1985), reafirmam algumas das conclusões apresentadas no diagnóstico do primeiro estudo. São elas:

1. Sobreposição não integrada de diferentes modalidades de atendimentos.

1.1 Creches, pré-escolas e atendimentos informais.

1.2 Áreas de saúde, alimentação assistência e educação.

2. Sobreposição dos órgãos responsáveis.

2.1 Instâncias federal, estaduais e municipais.

2.2 Diversos órgãos e programas sobrepondo-se em cada instância.

2.3 Criação contínua de novos órgãos e programas que se adicionam aos já existentes.

3. Atuação pública direta e a prática de convênios.

3.1 Oscilações e desencontros entre os dois tipos de atuação.

3.2 Múltiplas formas de convênios, com exigências burocráticas excessivas, atuando paralelamente, através de critérios extremamente diversificados.

3.3 População alvo considerada prioritária, variando conforme o órgão responsável e deixando alguns grupos a descoberto.

4. Problemas em relação à coleta de dados de cobertura dos vários tipos de atendimento.

4.1 Terminologia enganosa e pouco precisa adotada nos vários programas.

4.2 Sobreposição de dados a respeito do número de crianças atendidas, que podem ser as mesmas sob vários tipos de convênios.

4.3 Não inclusão da creche nas estatísticas educacionais.

5. Problemas em relação à avaliação de custos e benefícios dos programas.

5.1 Grande variação nos custos dos diversos programas.

\footnotetext{
${ }^{5}$ POPPOVIC, Ana Maria et al. Subsídios para elaboração de um programa nacional de atendimento à criança. São Paulo: Fundação Carlos Chagas, 1983.
} 
5.2 Desequilíbrio entre gastos com estruturas técnicas e burocráticas em comparação com gastos diretamente vinculados às unidades.

6. Legislação omissa.

7. Tendência à atuação crescente do nível municipal.

8. Pressão crescente da demanda, emergência de movimentos de reivindicação. (POPPOVIC et al., 1983 apud CAMPOS; ROSEMBERG; FERREIRA, 2001, p. 14).

Seis anos mais tarde, em 1989, Campos, Rosemberg e Ferreira (2001), ao introduzirem uma avaliação do texto constitucional no que se refere à educação infantil, salientam que esses problemas e tendências encontrados na primeira pesquisa, realizada em 1983, haviam subsistidos ou, ainda, agravados.

Esse era, portanto, o quadro da educação infantil logo após a promulgação do texto constitucional. A partir daquele período, observam-se tentativas de delimitar o campo específico da educação infantil, de definir terminologia apropriada, conceituar as instituições e traçar os seus objetivos, tendo em vista o direito à educação da criança de 0 a 6 anos e o direito das mães e pais trabalhadores. Segundo Nascimento (2003), o início da década de 1990 foi marcado pela discussão sobre a importância da infância, subsidiando a elaboração de documentos que salientam os direitos da criança e a importância da educação infantil, entre eles o Estatuto da Criança e do Adolescente (1990) e a Política Nacional para a Educação Infantil (1994).

\section{ECA - em defesa da garantia dos direitos da criança e do adolescente}

O ECA - Lei n ${ }^{\circ}$ 8.069/90 - foi elaborado e sancionado logo após a Constituição Federal (1988), contando com ampla participação de setores da sociedade civil na mobilização e redação de seu texto. Isto explica, para Corrêa (2002), o conteúdo significativo desta lei no que diz respeito à garantia dos direitos da infância e da adolescência, amplamente defendida por movimentos organizados em defesa desta faixa etária durante o processo de elaboração da nossa carta magna e que se mantiveram articulados após a sua promulgação.

$\mathrm{Na}$ realidade, afirma Bazilio (2006), o ECA incorporou a ação dos movimentos sociais da década de 1980. Nos primeiros cinco anos dessa década, pastorais, associações de moradores e outras entidades criticaram duramente o modelo de intervenção adotado pelo Estado em relação aos menores de 18 anos, e o mercado editorial publicou teses, pesquisas e matérias jornalísticas sobre o tema. Na segunda metade da mesma década, essas entidades, impulsionadas pelo fim da censura que possibilitou denunciar a ineficácia da ação da Fundação Nacional do Bem-Estar do Menor (FUNABEM) e das Fundações Estaduais do Bem-Estar do Menor (FEBEMs), pela redemocratização do país e pelo processo constituinte de 1988, desejaram e lutaram pelos direitos da infância. 
O panorama da criança e do adolescente no Brasil, especificamente no campo das políticas sociais, mudou a partir do ECA e da atual Constituição Federal. Nesse momento se reconheceu, na forma de lei, que as crianças e os adolescentes possuem direitos que podem ser exercitados junto à família, à sociedade e ao Estado.

Alguns pesquisadores consideram o ECA, ao complementar os dispositivos constitucionais, um marco político na história dos movimentos sociais em defesa da infância no Brasil (PINO, 1990; CORRÊEA, 2002; BAZÍLIO, 2006). Para Pino (1990, p. 61, grifos do autor), por exemplo, esta lei tem um importante significado político e jurídico: "De um lado, ela representa um gesto político de reconciliação legal do país com a sua infância. De outro lado, ela constitui o reconhecimento, também legal, do direito dessas crianças e desses jovens à cidadania, independentemente da classe social de origem".

Foi necessário um ano e meio de debates entre parlamentares e sociedade civil para a elaboração do texto do ECA, constituído de dois livros. O livro I, denominado Parte Geral, contém títulos que versam sobre a criança e os adolescentes como sujeitos de direitos fundamentais e individuais que devem ser assegurados com absoluta prioridade por toda a sociedade e pelo poder público. O livro II, denominado Parte Especial, aborda as políticas de atendimento, as medidas de proteção, a prática de infrações, as responsabilidades de pais e responsáveis, as atribuições do Conselho Tutelar e a forma de acesso à justiça.

Ao ser aprovado e promulgado, em 13 de julho de 1990, o ECA revogou a Lei n. 6.697/79 conhecida como Código de Menores. Pino (1990) salienta que não se trata apenas de uma alteração semântica. A mudança de nome revela a diferença de concepção de infância. A que inspirava o Código de Menores (1979) era de natureza discriminatória e repressiva, pois partia do princípio de que os indivíduos com idade inferior a 18 anos provenientes de famílias pobres tendiam a provocar desordens sociais e, para tanto, era necessário tomar medidas preventivas e de controle social.

Por adotar o princípio da proteção integral de todas as crianças e adolescentes, o ECA inaugura outra concepção de infância assentada nos direitos fundamentais reconhecidos pela Convenção Internacional sobre os Direitos da Criança, adotada pela Organização das Nações Unidas - ONU, em 1989, e ratificada pelo Brasil no ano seguinte. Com a adoção dessa doutrina, os direitos da criança e do adolescente são vistos de uma perspectiva condizente com a sua condição de pessoa em desenvolvimento e que, por sua vulnerabilidade, merecem proteção integral: física, psíquica e moral. É o que diz o Art. $3^{\circ}$ da referida lei, revelando a importância conferida a estes dois grupos etários: 
A criança e o adolescente gozam de todos os direitos fundamentais inerentes à pessoa humana, sem prejuízo da proteção integral de que trata esta Lei, assegurando-se-lhes, por lei ou por outros meios, todas as oportunidades e facilidades, a fim de lhes facultar o desenvolvimento físico, mental, espiritual e social, em condições de liberdade e de dignidade. (BRASIL, 1990).

Com essa visão, o ECA rompeu com a concepção de infância como categoria universal e homogênea. Esta etapa do desenvolvimento humano passou a ser concebida, segundo Nascimento (2003, p. 70), como "categoria historicamente emergente". Nesta perspectiva, a criança é vista como "[...] pessoa em desenvolvimento, protagonista de sua própria vida, agente e produto da vida social"'.

Segundo Pino (1990), a concepção de infância presente no ECA está fundada em dois princípios: um deles afirma que todas as crianças e adolescentes são sujeitos de direito, independente de sua condição econômica e social, os quais devem ser assegurados pelo Estado e pela sociedade; o outro concebe a pobreza e o abandono social como problemas sociais cuja solução requer reformas educacionais, econômicas e implementação de políticas sociais que garantam o cumprimento dos constitucionais.

Com pequenas variantes, o ECA reproduz, em seu Art. $4^{\circ}$, o que dispõe o Art. 227 da atual Constituição, confirmando que aos direitos da criança deve ser dada absoluta prioridade, ou seja, eles devem ter preferência na formulação e na execução das políticas sociais e na destinação de recursos públicos (PINO, 1990). Nos termos da lei:

É dever da família, da comunidade, da sociedade em geral e do Poder Público assegurar, com absoluta prioridade, a efetivação dos direitos referentes à vida, à saúde, à alimentação, à educação, ao esporte, ao lazer, à profissionalização, à cultura, à dignidade, ao respeito, à liberdade e à convivência familiar e comunitária. (BRASIL, 1990).

A parte referente aos Direitos Fundamentais da Criança e do Adolescente (Art. 7 ao 69) é considerada a mais importante do ECA por esmiuçar o exposto no Art. 227 da Constituição (AGUIAR, 1994). Nela, os direitos da infância foram agrupados em quatro grandes categorias: direito à vida e à saúde; direito à liberdade, ao respeito e à dignidade; direito à educação; direito à vida familiar e comunitária (PINO, 1990). O capítulo IV, Do Direito à Educação, à Cultura, ao Esporte e ao Lazer (Art. 53 ao 59), está localizado nessa parte do documento. No Art. 53, ele reafirma que

A criança e o adolescente têm direito à educação, visando ao pleno desenvolvimento de sua pessoa, preparo para o exercício da cidadania e qualificação para o trabalho, assegurando-lhes: 
I. igualdade de condições para o acesso e permanência na escola;

II. direito de ser respeitado por seus educadores;

III. direitos de contestar critérios avaliativos, podendo recorrer às instâncias escolares superiores;

IV. direito de organização e participação em entidades estudantis;

V. acesso à escola pública e gratuita próxima de sua residência.

Parágrafo único - É direito dos pais ou responsáveis ter ciência do processo pedagógico, bem como participar da definição das propostas educacionais. (BRASIL, 1990).

O ECA, pautando-se em princípios da democracia participativa e da descentralização administrativa, prevê a criação de conselhos tutelares formados por representantes de órgãos públicos e de organizações não-governamentais. Além disso, por ter objetivos amplos, permite atender à criança e ao adolescente de forma global por meio da associação entre educação e assistência. (ZANNINI, 2002, p. 22).

Referência à educação infantil é feita somente no inciso IV do Art. 54, que reforça o dispositivo da Lei Maior (Art. 208), que afirma o dever do Estado para com a educação das crianças de 0 a 6 anos, as quais devem ser atendidas em creches e pré-escolas. Para Didonet (1992), apesar de o ECA ter alterado radicalmente a legislação anterior, ter sido considerado pela UNICEF uma das legislações mais avançadas do mundo na área dos direitos da criança e do adolescente, ter promovido mudanças na realidade das crianças e dos adolescentes brasileiros, não avançou, na área da educação infantil, em relação à Constituição (1988). O autor salienta que esse assunto é próprio da Política Nacional de Educação Infantil e da LDB, ambas, naquele momento, em fase de elaboração.

\section{Política Nacional de Educação Infantil - em busca de expansão e de qualidade}

A educação infantil, embora se expandindo e ganhando espaço nos planos de educação de âmbito nacional e das secretarias de educação, ressentia-se da falta de legislação que tratasse de sua especificidade. (MUNERATO, 2001). O direito à educação da criança de 0 a 6 anos, reconhecido na Constituição Federal e reafirmado pelo ECA, suscitou grande movimentação do MEC, que contava, naquele momento, com o apoio de um número expressivo de especialistas e pesquisadores da área. Por isso, a Coordenação de Educação Infantil (COEDI), norteada pelos parâmetros da Constituição, especialmente os de descentralização político-administrativa e de participação da sociedade por meio de organismos representativos, elaborou uma proposta nacional de política de educação infantil. 
Várias universidades, movimentos sociais, partidos políticos, associações de professores e outros segmentos da sociedade colaboraram para a elaboração dessa proposta. Seus princípios gerais compõem o documento intitulado Política Nacional de Educação Infantil - PNEI (1994). Esse documento propõe uma educação infantil que se afaste do modelo não-formal a baixo investimento público, característico do período anterior ${ }^{6}$, e adota metas de expansão com atendimento de qualidade.

As discussões para a formulação desse documento tiveram início em outubro de 1993 e culminaram com a realização, em Brasília, em agosto de 1994, do I Simpósio Nacional de Educação Infantil, quando foi aprovada a proposta do MEC como texto definitivo da PNEI. Vale salientar que ele reafirma o compromisso do Estado para com a educação das crianças nos seus primeiros anos de vida, referindo-se à educação infantil como primeira etapa da educação básica, tendência presente nos dois projetos de LDB, os quais, naquela época, tramitavam no Congresso Nacional.

Vale a pena salientar que, juntamente com a elaboração e divulgação da PNEI, outros documentos foram produzidos e publicados, no Governo Itamar Franco, pelo MEC e pelo Conselho Nacional de Educação (CNE), no sentido de apoiar os sistemas no estabelecimento de suas políticas para a educação infantil. Entre eles citamos: Por uma política de formação do profissional de educação infantil (1994); Educação infantil no Brasil: situação atual (1994); Educação infantil: bibliografia anotada (1995); Critérios para um atendimento em creches e pré-escolas que respeite os direitos fundamentais das crianças (1995); Propostas pedagógicas e currículo em educação infantil (1996).

A PNEI apresenta um breve balanço da situação da educação infantil brasileira, reconhecendo os seguintes fatos: as crianças de 4 a 6 anos têm mais acesso a essa etapa de formação que as crianças com idade inferior; o atendimento público supera quantitativamente o privado; as crianças atendidas são provenientes de áreas urbanas que concentram as populações de renda mais baixa; a deterioração na qualidade do atendimento às crianças, em especial as de 0 a 3

\footnotetext{
${ }^{6}$ Estamos nos referindo ao período compreendido entre o final da década de 1970 e o final da de 1980 , o qual corresponde à implantação de um modelo de educação infantil marcado pela influência do UNICEF e da UNESCO. As políticas econômicas e sociais destes organismos para a educação dos países em desenvolvimento tinham a finalidade de compensar as carências das crianças oriundas de famílias pobres, despendendo poucas verbas do Estado e utilizando recursos da comunidade, ou seja, eram de cunho compensatório. Esta foi a marca do 'Programa Educação Pré-Escolar: Uma Nova Perspectiva' (1975) e do 'Projeto Casulo' (1977). As críticas desferidas a esses programas que objetivavam recuperar déficits cognitivos, afetivos, nutricionais, linguísticos das crianças pobres foram absorvidas pelos órgãos oficiais ao lançarem o 'Programa Nacional de Educação Pré-Escolar' (1981) conferindo à educação infantil o papel de promover o desenvolvimento harmônico e global das crianças. Contudo, os efeitos da influência do UNICEF e da UNESCO na definição da função da educação infantil brasileira, nas décadas de 1970 e 1980, deixaram heranças, favoráveis ou não, que alicerçaram os passos dados em direção a uma educação infantil que visasse promover, concomitantemente, o cuidado e a educação das crianças pequenas.
} 
anos; a insuficiência e inadequação de espaços físicos, equipamentos e materiais pedagógicos; a dissociação entre as funções de educar e cuidar; a inexistência de currículos e propostas pedagógicas; a desvalorização e a falta de formação específica dos profissionais que atuam na área (BRASIL, 1994).

Com base nesse balanço, são apresentados os princípios, as diretrizes gerais, os objetivos e as linhas de ação prioritárias para orientar o trabalho do MEC para com a educação da criança de 0 a 6 anos. Como princípios norteadores da PNEI, destacamos:

1. A Educação Infantil é a primeira etapa da Educação Básica e destina-se à criança de zero a seis anos de idade, não sendo obrigatória, mas um direito a que o Estado tem obrigação de atender.

2. As instituições que oferecem Educação Infantil, integrantes dos Sistemas de Ensino, são as creches e as pré-escolas, dividindo-se a clientela entre elas pelo critério exclusivo da faixa etária (zero a três na creche e quatro a seis na pré-escola).

3. A Educação Infantil é oferecida para, em complementação à ação da família, proporcionar condições adequadas de desenvolvimento físico, emocional, cognitivo e social da criança e promover a ampliação de suas experiências e conhecimentos, estimulando seu interesse pelo processo de transformação da natureza e pela convivência em sociedade.

4. As ações de educação, na creche e na pré-escola, devem ser complementadas pelas de saúde e assistência, realizadas de forma articulada com os setores competentes.

5. O currículo de Educação Infantil deve levar em conta, na sua concepção e administração, o grau de desenvolvimento da criança, a diversidade social e cultural das populações infantis e os conhecimentos que se pretendem universalizar.

6. Os profissionais de Educação Infantil devem ser formados em cursos de nível médio ou superior, que contemplem conteúdos específicos relativos a essa etapa da educação.

7. As crianças com necessidades especiais devem, sempre que possível, ser atendidas na rede regular de creches e pré-escolas. (BRASIL, 1994, p. 15-16).

Esses princípios serviram de base para o estabelecimento das diretrizes pedagógicas e de política de recursos humanos da PNEI. Segundo esse documento, as diretrizes pedagógicas podem fazer com que as ações a serem efetivadas dentro de instituições de educação infantil sejam educativas. Sugere-se que essas ações sejam organizadas sob a forma de proposta pedagógica, que, por sua vez, deve estar fundamentada em uma concepção de criança, de educação infantil e de desenvolvimento. 
A PNEI concebe a criança como um sujeito social e histórico, ou seja, pertencente a uma família que, por sua vez, está inserida em uma sociedade. Ela é um ser completo, mas em processo de desenvolvimento, dependendo do adulto para sobreviver, crescer e ampliar seus conhecimentos e experiências. Para tanto, faz-se necessário que ela estabeleça relações não apenas com a família, ponto de referência importante para o seu desenvolvimento, mas com outras instituições sociais, como creches e pré-escolas, no qual possa interagir com diferentes pessoas, sejam adultas ou crianças. Nesse sentido, a PNEI destaca o papel preponderante da interação no processo de aprendizagem e desenvolvimento, salientando que, no caso das crianças, deve ocorrer de forma lúdica e afetiva.

Tal documento, ao elucidar suas diretrizes pedagógicas, lembra que o desenvolvimento infantil, apesar de seguir caminhos semelhantes em todas as crianças, obedece a formas e ritmos peculiares a cada uma delas. Isso exige da educação infantil o cumprimento de duas funções complementares e indissociáveis: cuidar e educar. Cabe-lhe:

(1) favorecer o desenvolvimento infantil, nos aspectos físico, motor, emocional, intelectual e social; (2) promover a ampliação das experiências e dos conhecimentos infantis, estimulando o interesse da criança pequena pelo processo de transformação da natureza e pela dinâmica da vida social, e, (3) contribuir para que sua interação e convivência na sociedade seja produtiva e marcada pelos valores de solidariedade, liberdade, cooperação e respeito. (BRASIL, 1994, p. 17).

Uma educação infantil com tal função requer um profissional que saiba organizar o ambiente educativo, planejar suas ações, iniciar e propor atividades junto às crianças; avaliar, a cada momento, as expectativas, os desejos, as necessidades e o nível de desenvolvimento e aprendizagem das crianças. Enfim, utilizando expressão do documento em análise, que tenha intenção educativa.

A um profissional com tamanha incumbência devem ser asseguradas condições de trabalho, plano de carreira, salário condigno e formação condizente a essas exigências. Para tanto, a PNEI traça diretrizes para uma política de recursos humanos. Tais diretrizes enfatizam que o profissional de educação infantil tem a função de educar e cuidar, de forma integrada, as crianças de 0 a 6 anos de idade; deve ser valorizado no que diz respeito às condições de trabalho, plano de carreira e remuneração; deve ter formação inicial em nível médio e superior; deve ter acesso a formas de atualização ou especialização profissional; e, se não possui a formação mínima exigida, que lhe sejam oferecidas condições para obtê-la em um prazo de 8 anos.

Com base nas diretrizes anteriormente expostas, três objetivos são estabelecidos pela PNEI como imediatos: 
1. expandir a oferta de vagas para a criança de zero a seis anos;

2. fortalecer, nas instâncias competentes, a concepção de educação infantil definida neste documento;

3. promover a melhoria da qualidade do atendimento em creches e préescolas. (BRASIL, 1994, p. 21).

Para que esses objetivos possam ser alcançados, o documento destaca a necessidade de concentração de esforços por meio de alianças entre o MEC, instituições não-governamentais e representações da sociedade civil. Com vistas a orientar o trabalho conjunto dessas instâncias, são estabelecidas sete ações prioritárias (BRASIL, 1994):

1. definição e implementação, com as demais instâncias competentes, de metas e estratégias de expansão e melhoria da qualidade da educação infantil;

2. eficiência e equalização no financiamento;

3. incentivo à elaboração, implementação e avaliação de propostas pedagógicas e curriculares, especialmente àquelas que visem à promoção da função educativa da creche;

4. promoção da formação e valorização dos profissionais de educação infantil;

5. promoção da integração de ações interdisciplinares e intersetoriais de atenção à criança;

6. criação de um sistema de informações sobre a educação infantil;

7. incentivo à produção e divulgação de conhecimento na área de educação infantil.

Dentre essas prioridades, Rosemberg destaca duas por evidenciarem uma ruptura com o modelo de educação infantil anterior. São elas: "[...] equivalência de creches e pré-escolas, ambas tendo por função cuidar e educar crianças pequenas como expressão do direito à educação; formação equivalente para o profissional de creche e pré-escola em nível secundário e superior". (ROSEMBERG, 2002a, p. 12).

A implantação dessas propostas presentes na PNEI foi interrompida, segundo Rosemberg (2002a), pela administração federal no governo de Fernando Henrique Cardoso (1995-1998/1999-2002), que, ao encabeçar a reforma do Estado brasileiro, incorporou nos planos econômicos, os princípios do Fundo Monetário Internacional e, nas políticas educacionais, as orientações do Banco Internacional de Desenvolvimento e, principalmente, do Banco Mundial. Essa reforma do Estado ocorreu atrelada a razões econômicas marcadas pela globalização da economia, desencadeando modificações sociais que, consequentemente, levaram a América Latina, em especial, a substituir os modelos de políticas sociais, passando a enfatizar a eficiência, a redução do 
papel do Estado e o aumento da participação da iniciativa privada no mercado. Esta direção corroborou para o alargamento do debate sobre os direitos que a sociedade civil organizada havia conquistado no período marcado pelo processo constituinte da década anterior. (BAZÍLIO, 2006).

\section{Algumas considerações finais}

Verificamos que o segundo período da história da educação infantil brasileira contemporânea, conforme a periodização feita por Rosemberg (2003), foi marcado por significativa participação da sociedade civil e de organismos governamentais na discussão e afirmação dos direitos da criança. Para demonstrar o envolvimento da sociedade neste movimento, Didonet (1992) relata a marcante participação, inclusive das crianças:

Nas escolas, elas estudavam e debatiam sobre seus direitos e sobre os problemas reais que estavam enfrentando. Nas ruas, elas iam em busca de assinaturas de outras crianças e de adultos em apoio às reivindicações que seriam encaminhadas à Assembléia Nacional Constituinte. Nas praças, elas realizavam dias de mobilização, de desenho sobre seus direitos. Em assembléias legislativas e câmara de vereadores, realizavam simulações de sessões nas quais debatiam suas questões, com a assistência de deputados e vereadores. Marchas e passeatas, concursos de redação e de desenho, cartas aos constituintes, participação em programas de rádio e de televisão, foram outras formas que as crianças utilizaram para expressar como desejavam que a sociedade as visse e com elas se relacionasse. (DIDONET, 1992, p. 26-27).

A mobilização se deu em torno da defesa de uma política integrada de educação da criança de 0 a 6 anos em oposição às concepções essencialmente assistencialistas e preparatórias que, até então, caracterizavam o atendimento às crianças pequenas. $\mathrm{O}$ texto constitucional as reconheceu como cidadãs, ao conferir-lhes, entre outros, o direito de serem atendidas em creches e pré-escolas, e o dever de o Estado garantir tal atendimento.

Em sintonia com essa tendência, o ECA reforçou o compromisso do Estado para com a educação das crianças com idade entre 0 e 6 anos e, para especificar esse direito e reforçar a necessidade de afastar a educação infantil do modelo característico do período anterior, a PNEI definiu como finalidade desse nível de ensino proporcionar condições adequadas para o desenvolvimento físico, emocional, cognitivo e social das crianças, ampliando suas experiências e promovendo conhecimento. Isso exige desse nível de escolaridade o cumprimento de duas funções complementares e indissociáveis: cuidar e educar. Contudo, este documento não estava atrelado a definições de financiamento que poderiam garantir a sua implementação. Consequentemente, tais políticas dificilmente sairiam do papel. 
Como demonstramos ao longo do texto, os avanços que marcaram o período estudado deram-se no âmbito da legislação. No efetivo atendimento à criança pequena os avanços foram poucos e lentos. Mudanças mais concretas passaram a ocorrer com a LDB (1996), quando o MEC e o CNE elaboraram normativas e distintas diretrizes com orientações mais claras visando direcionar o trabalho a ser realizado na educação infantil e na formação de professores para atuarem nesse nível de ensino?.

Por fim, destacamos que o conhecimento do processo da produção do reconhecimento do direito da criança pequena à educação reforça a necessidade de continuação da luta para que o Estado cumpra o seu papel: garantir esse direito. Esse é o desafio que se coloca para educadores e para a sociedade civil no início do século XXI.

\section{Referências}

ABRAMOVAY, M.; KRAMER, S. “O rei está nu”: um debate sobre as funções da pré-escola. Cadernos CEDES, Campinas, n. 9, p. 27-38, 1984.

AGUIAR, U. Financiamento da educação infantil. In: SIMPÓSIO NACIONAL DE EDUCAÇÃO INFANTIL, 1., Brasília. Anais... Brasília: MEC/SEF/DPE/COEDI, 1994. p. $57-62$.

BARRETO, Â. M. R. F. Educação infantil no Brasil: desafios colocados. Cadernos CEDES, Campinas, n. 37, p. 7-21, 1995.

BARRETTO, E. S. de S. Os sistemas municipais de ensino e a educação infantil. In: MACHADO, M. L. de A. (Org.). Educação infantil em tempos de LDB. São Paulo: FCC/ DPE, 2000. p. 25-40.

BAZÍLIO, L. C. Avaliando a implantação do Estatuto da Criança e do Adolescente. In: .; KRAMER, S. Infância, educação e direitos humanos. São Paulo: Cortez, 2006. p. 19-28.

BRASIL. Constituição da República Federativa do Brasil. Brasília: Senado, 1988.

. Lei n. 8.069 de 13 julho de 1990. Estatuto da Criança e do Adolescente. Diário Oficial da União, Brasília. 16 jul. 1990.

Ministério da Educação e do Desporto. Secretaria de Educação Fundamental.

Política Nacional de Educação Infantil. Brasília: MEC/SEF/DPE/COEDI, 1994.

- Ministério da Educação e do Desporto. Secretaria de Educação Fundamental. Por uma política de formação do profissional de Educação Infantil. Brasília: MEC/SEF/ DPE/COEDI, 1994.

\footnotetext{
${ }^{7}$ Referencial Curricular Nacional para a Educação Infantil (1998); Diretrizes Curriculares Nacionais para a Educação Infantil (1999); Diretrizes Operacionais para a Educação Infantil (2000); Diretrizes Curriculares Nacionais para a Formação de Docentes da Educação Infantil e dos anos iniciais do Ensino Fundamental, em nível médio, na modalidade Normal (1999); Diretrizes Curriculares Nacionais para a Formação de Professores da Educação Básica, em nível superior, curso de licenciatura, de graduação plena (2002).
} 
Ministério da Educação e do Desporto. Secretaria de Educação Fundamental. Educação infantil no Brasil: situação atual. Brasília: MEC/SEF/DPE/COEDI, 1994.

Ministério da Educação e do Desporto. Secretaria de Educação Fundamental. Educação infantil: bibliografia anotada. Brasília: MEC/SEF/DPE/COEDI, 1995.

Ministério da Educação e do Desporto. Secretaria de Educação Fundamental. Critérios para um atendimento em creches e pré-escolas que respeite os direitos fundamentais das crianças. Brasília: MEC/SEF/DPE/COEDI, 1995.

Ministério da Educação e do Desporto. Secretaria de Educação Fundamental. Propostas pedagógicas e currículo em educação infantil. Brasília: MEC/SEF/DPE/ COEDI, 1996.

- Ministério da Educação e do Desporto. Secretaria de Educação Fundamental.

Referencial Curricular Nacional para a Educação Infantil. Brasília: MEC/SEF/ COEDI, 1998.

. Resolução CNE/CEB n. 1, 7 de abril de 1999. Diretrizes Curriculares Nacionais para a Educação Infantil. Brasília: CNE/CEB, 1999.

Resolução CNE/CEB n. 2, 19 de abril de 1999. Diretrizes Curriculares Nacionais para a Formação de Docentes da Educação Infantil e dos anos iniciais do Ensino Fundamental, em nível médio, na modalidade Normal. Brasília: CNE/CEB, 1999.

Parecer CNE/CEB n. 4, 16 de fevereiro de 2000. Diretrizes Operacionais para a Educação Infantil. Brasília: CNE/CEB, 2000.

Resolução CNE/CP n. 1, 18 de fevereiro de 2002. Diretrizes Curriculares Nacionais para a Formação de Professores da Educação Básica, em nível superior, curso de licenciatura, de graduação plena. Brasília: CNE/CP, 2002.

CAMPOS, M. M. A constituinte e a educação da criança de 0 a 6 anos. Cadernos CEDES, São Paulo, n. 59, p. 57-65, 1986.

CAMPOS, M. M.; ROSEMBERG, F.; FERREIRA, I. M. Creches e pré-escolas no Brasil. São Paulo: Cortez; Fundação Carlos Chagas, 2001.

CORRÊA, B. C. Educação infantil. In: OLIVEIRA, R. P.; ADRIÃO, T. (Orgs.). Organização do ensino no Brasil: níveis e modalidades na Constituição Federal e na LDB. São Paulo: Xamã, 2002. p. 17-28.

CRAIDY, C. M. A educação da criança de 0 a 6 anos: o embate assistência e educação na conjuntura nacional e internacional. In: MACHADO, M. L.A. (Org.). Encontros e desencontros em educação infantil. São Paulo: Cortez, 2002. p. 57-63.

DIDONET, V. Balanço crítico da educação pré-escolar nos anos 80 e perspectivas para a década de 90. Em aberto, Brasília, v. 10, n. 50/51, p. 19-33, abr./set. 1992.

KRAMER, S. A política do pré-escolar no Brasil: a arte do disfarce. Rio de Janeiro: Dois pontos, 1987.

MUNERATO, R. V. S. Educação infantil: políticas públicas na década de 80. Bauru: EDUS, 2001. 
NASCIMENTO, M. L. Anos 90: políticas públicas frente a um novo paradigma nas concepções de infância e educação. In: SÃO PAULO. Secretaria de Estado da Educação. PEC Formação Universitária: Municípios: Educação Infantil. São Paulo: SEE, 2003. p. 69-77.

OLIVEIRA, S. M. L. A legislação e as políticas nacionais para a educação infantil: avanços, vazios e desvios. In: MACHADO, M. L. A. (Org.). Encontros e desencontros em educação infantil. São Paulo: Cortez, 2002. p. 35-42.

PINO, A. Direitos e realidade social da criança no Brasil: a propósito do "Estatuto da Criança e do Adolescente”. Educação \& Sociedade, Campinas, n. 36, p. 61-79, ago. 1990.

ROSEMBERG, F. Do embate para o debate: educação e assistência no campo da educação infantil. MACHADO, M. L. A. (Org.). Encontros e desencontros em educação infantil. São Paulo: Cortez, 2002a. p. 63-78.

Organizações multilaterais, estado e políticas de educação infantil. Cadernos de Pesquisa, São Paulo, n. 115, mar. 2002b. DOI: 10.1590/S0100-15742002000100002

- Panorama da educação infantil brasileira contemporânea. In: SIMPÓSIO EDUCAÇÃO INFANTIL: CONSTRUINDO O PRESENTE, Brasília. Anais... Brasília: UNESCO, 2003. p. 33-81.

VIEIRA, S. L. A educação nas constituições brasileiras: texto e contexto. Revista Brasileira de Estudos Pedagógicos, Brasília, v. 88, n. 219, p. 291-309, maio/ago. 2007.

VILLALOBOS, V. S. O estado do bem-estar social na América Latina: necessidade de redefinição. Cadernos Adenauer, n. 1, p. 49-70, 2000.

ZANINNI, C. C. Educação infantil enquanto direito. In: MIEIB. Movimento Interfóruns de Educação Infantil do Brasil. Educação infantil: construindo o presente. Campo Grande: Ed. UFMS, 2002. p. 19-42.

Recebido em 03/09/2011

Versão final recebida em 12/02/2012

Aceito em 25/03/2012 